\title{
Temperature Effects on the Microstructures of Mg-Gd-Y Alloy Processed by Multi-direction Impact Forging
}

\author{
S. S. A. Shah ${ }^{1,2} \cdot$ D. Wu ${ }^{2} \cdot$ R. S. Chen ${ }^{2} \cdot$ G. S. Song ${ }^{1}$ \\ Received: 11 June 2019 / Revised: 14 September 2019 / Published online: 2 December 2019 \\ (c) The Chinese Society for Metals (CSM) and Springer-Verlag GmbH Germany, part of Springer Nature 2019
}

\begin{abstract}
A high strain rate multi-directional impact forging (MDIF) was applied to a solutionized $\mathrm{Mg}-\mathrm{Gd}-\mathrm{Y}-\mathrm{Zr}$ alloy in the temperature range of $350-500^{\circ} \mathrm{C}$. Results demonstrate that the dominant deformation mode is twinning at a temperature below $400{ }^{\circ} \mathrm{C}$, whereas at a medium temperature of $450{ }^{\circ} \mathrm{C}$ considerable continuous dynamic recrystallization was promoted by $\{10-12\}$ extension twins. At a higher temperature of $500{ }^{\circ} \mathrm{C}$, twinning activation was suppressed. New DRX grains were observed but their sizes were much bigger than those resulting from the MDIFed 50 passes at $450{ }^{\circ} \mathrm{C}$, which are ascribed to the larger grain boundary mobility and atomic diffusion at $500{ }^{\circ} \mathrm{C}$. Moreover, a non-basal weak texture was gained afterward MDIF at each temperature, which is credited to the MDIF process and the minor strain applied in each pass.
\end{abstract}

Keywords Magnesium alloys $\cdot$ Twinning $\cdot$ Dynamic recrystallization $\cdot$ Forging $\cdot$ Texture

\section{Introduction}

$\mathrm{Mg}$ alloys attracted significant research interests in aerospace, automotive, power tools, and 3C (i.e., computer, communication, and consumer electronics products) industries $[1,2]$. In comparison to the components made from aluminum and iron-based materials, $\mathrm{Mg}$ alloys have the capability to reduce their weight by $37 \%$ and $78 \%$, respectively $[3,4]$. This weight-reducing capacity is eco-friendly and directly related to the decrease in fuel consumption.

In the recent decade, $\mathrm{Mg}$ alloys containing $\mathrm{Gd}$ and $\mathrm{Y}$ specifically $(\mathrm{Mg}-\mathrm{Gd}-\mathrm{Y})$ have attracted numerous research interests $[5,6]$, since they possess high strength at the room as well as at ambient temperatures and demonstrate good

Available online at http://link.springer.com/journal/40195

S. S. A. Shah and D. Wu have contributed equally to this work.

R. S. Chen

rschen@imr.ac.cn

G. S. Song

song_ahut@163.com

1 School of Material Science and Engineering, Anhui University of Technology, Ma'anshan 243032, China

2 The Group of Magnesium Alloys and Their Applications, Institute of Metal Research, Chinese Academy of Sciences, 62 Wencui Road, Shenyang 110016, China creep resistance $[7,8]$. To understand their microstructure evolution, several investigations were reported on dynamic recrystallization (DRX) behavior via extrusion [7, 9] rolling [10,11], and compression [12] processes. Such as Hong et al. [12] confirmed that the long-period stackingordered (LPSO) phases play an essential role in the dynamic recrystallization of $\mathrm{Mg}-11 \mathrm{Gd}-4 \mathrm{Y}-2 \mathrm{Zn}-0.4 \mathrm{Zr}$ alloy during the hot compression. Yu et al. [13] observed the increase in the volume fraction of Mg5RE phases along with the improving DRX with the increase in extrusion ratio, while increasing the extrusion temperature decreases the volume fraction of Mg5RE phase and coarsens the DRXed grains. Similarly, Wang et al. [14] confirmed the basal and prismatic slip as dominant, while the pyramidal slip and extension twinning as the complementary deformation modes in $\mathrm{Mg}-\mathrm{Gd}-\mathrm{Y}-\mathrm{Zn}-\mathrm{Mn}$ alloy sheets processed by large-strain high-efficiency rolling. So far, about multi-directional forging few reports could be found on the temperature effects on microstructure evolution of $\mathrm{Mg}-\mathrm{Gd}-\mathrm{Y}$ alloy which reflects their poor workability during the traditional forging process.

Regarding MDF, the $\mathrm{Mg}$ alloys such as $\mathrm{Mg}-\mathrm{Al}-\mathrm{Zn}$ alloys [15], AZ series [16, 17] (RE free Mg alloys) were still concerned via MDF. Wu et al. [18] applied MDF on the ZK21 Mg alloy and due to the different strain rate applied experienced different twinning and DRX behavior. They attributed the island-like ultrafine DRX structure to the higher twinning density while grain coarsening to the 
adiabatic rise in temperature during forging. Miura et al. [15] processed $\mathrm{Mg}-\mathrm{Al}-\mathrm{Zn}$ alloy at room temperature by multidirectional forging and experience the division of initial coarse grains into ultrafine grains by twinning activation. They found twins acting as more preferential nucleation sites than the grain boundaries for recrystallization. Indeed, MDF was also carried out on $\mathrm{Mg}-\mathrm{Gd}-\mathrm{Y}$ alloy [19]; however, with such a low strain rate traditional hydrostatic forging technique, the authors did not perceive twins inside the microstructure which can promote an obvious DRX behavior.

In the present study, we successfully processed a Mg-9.02Gd-4.21Y-0.48Zr wt\% (GW94) alloy via highspeed multi-direction impact forging (MDIF) and found it an efficient method to modify the coarse granular structure by twinning activation, which consequently promotes the dynamic recrystallization (DRX) behavior. MDIF also supported the recrystallization process in AZ61 Mg alloy [16], mainly by twin induced DRX behavior and non-basal textures.

In addition, many reports have addressed the topic of strain rate effects on DRX and twinning behavior in $\mathrm{Mg}$ alloys [1,20]; however, little research has been conducted on the temperature effects during the high strain rate forging process especially in $\mathrm{Mg}-\mathrm{Gd}-\mathrm{Y}$ system alloys. Thus, the current work attempts to analyze the effect of deformation temperature on the twinning activity and DRX behavior during the MDIF process which would provide beneficial understanding to obtain a homogeneous and fine-grained $\mathrm{Mg}-\mathrm{Gd}-\mathrm{Y}$ alloy.

\section{Experimental}

The GW94 Mg alloy samples were extracted in cubic block shape (as-cast ingot) with magnitudes of $70 \mathrm{~mm}$ length $\times 70 \mathrm{~mm}$ width $\times 70 \mathrm{~mm}$ height. The samples were processed through solutionization treatment at $525{ }^{\circ} \mathrm{C}$ for $10 \mathrm{~h}$, which were then cooled in the air down to room temperature.

A hammer (industrial air pneumatic machine) loaded with $400 \mathrm{~kg}$ was used to carry out the MDIF process in the open air as mentioned in detail in Ref. [8]. The strain rate was about $50 \mathrm{~s}^{-1}$, and small strain per pass of $\sim 0.05$ was employed during the MDIF process. Meanwhile, during the MDIF process, the sample direction was changed by $90^{\circ}$ every pass and the specimens were forged for 30 passes as shown in the schematic (Fig. 1a). As the pass strain was applied pass by pass from each side, almost no change in the final shape of the samples was observed. In total, four samples were impact forged; however, each one was heated to a different temperature before MDIF, i.e., $350{ }^{\circ} \mathrm{C}, 400{ }^{\circ} \mathrm{C}$, $450{ }^{\circ} \mathrm{C}$, and $500{ }^{\circ} \mathrm{C}$ for $1 \mathrm{~h}$. In addition, the sample forged for 30 passes at $450{ }^{\circ} \mathrm{C}$ was extended to 50 passes as exposed in Fig. 1b. Since MDIF was carried out in an open atmosphere, temperature drop may also occur, however, due to the deformation-induced heating, the temperature loss was not larger than $\sim 25{ }^{\circ} \mathrm{C}$ of the samples. The specimens for microstructural characterizations were cut from the center of the MDIFed cubic sample. The X-ray diffraction, optical microscopy (OM), and electron backscatter diffraction (EBSD) results were obtained from the central plane perpendicular to the last forging direction as demonstrated in Fig. 1c. Scanning electron microscopy (SEM) model Philips XL 30 ESEM-FEG operational at $20 \mathrm{kV}$ was used to collect the EBSD results. The step size of $\sim 0.2 \mu \mathrm{m}$ was kept during measuring the EBSD orientation maps. $\{0002\}$ pole figures were obtained via DIFFRAC plus TEXEVAI software operated by X-ray diffraction Schultz reflection method.

\section{Results}

\subsection{Initial Microstructure}

Figure 2a-c reveals the typical optical and SEM microstructures of the as-cast and solutionized GW94 alloy. The ascast alloy revealed relatively fine grains surrounded by nonequilibrium coarse eutectic $\beta$-phases (Fig. 2a). About these non-equilibrium phases including cuboid-shaped particles, we have debated in our previous report [3, 8]. In brief, these non-equilibrium phases were studied in detail by Gao et al. [21] and they confirmed them as $\mathrm{Mg} 24(\mathrm{Gd}, \mathrm{Y}) 5$, by transmission electron microscopy (TEM). The non-equilibrium coarse eutectic phases were almost dissolved in the matrix afterward the solution treatment at $525^{\circ} \mathrm{C} \times 10 \mathrm{~h}$ (Fig. 2b), however, still some cuboid-shaped $\mathrm{Mg} 5(\mathrm{Gd}, \mathrm{Y})$ [21] particles persisted throughout the microstructure (Fig. 2c). Nevertheless, the same cuboid phases in $\mathrm{Mg}-\mathrm{Gd}-\mathrm{Y}$ alloy were studied by $\mathrm{Li}$ et al. [22] and they recognized them as $\mathrm{YH}_{2}$ and few $\mathrm{GdH}_{2}$ phases. The average size of grains of the assolutionized sample increased from $\sim 90$ to $\sim 160 \mu \mathrm{m}$.

\subsection{Microstructural Evolution During MDIF at Different Temperatures}

The optical microstructures of GW94 alloy with 30 forging passes at temperature $350{ }^{\circ} \mathrm{C}, 400{ }^{\circ} \mathrm{C}, 450{ }^{\circ} \mathrm{C}$ and $500{ }^{\circ} \mathrm{C}$ are illustrated in Fig. 3. As shown in Fig. 3a, b, GW94 alloy MDIFed at $350{ }^{\circ} \mathrm{C}$ and $400{ }^{\circ} \mathrm{C}$ revealed almost the same microstructure and reflects negligible DRX grains. Twinning seems to be the dominant deformation mode at this temperature, as abundant lenticular twins were observed throughout the microstructure. However, some coarse original grains without twins were also noticed as pointed by the yellow arrows in Fig. 3a, b. At $450{ }^{\circ} \mathrm{C}$, when the alloy was forged, a considerable number of DRX grains appeared 
(a)

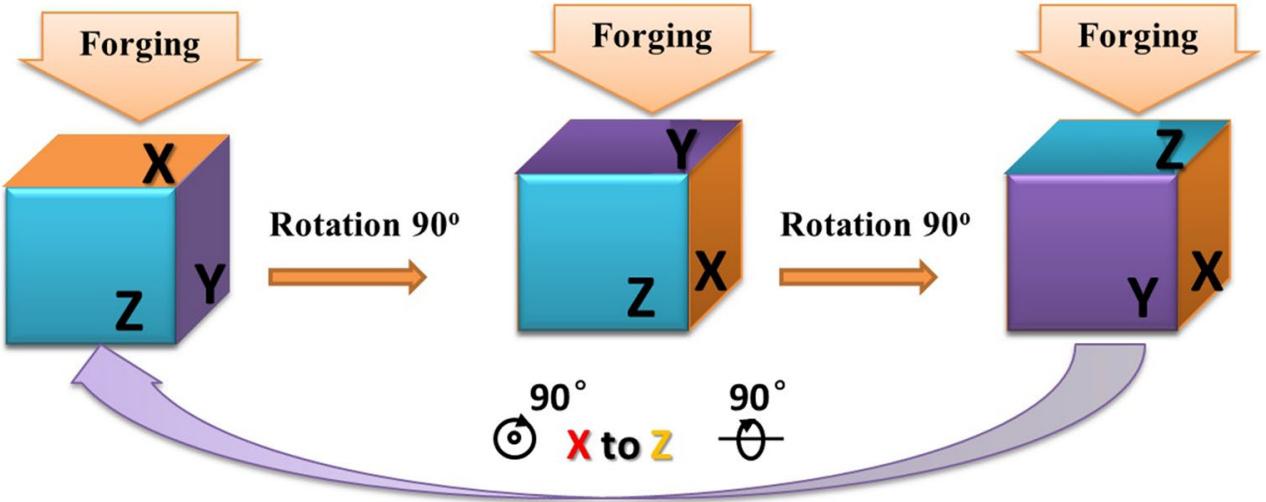

(b)

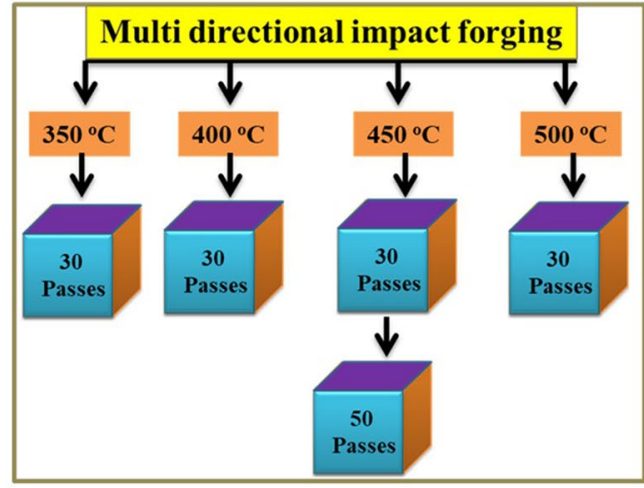

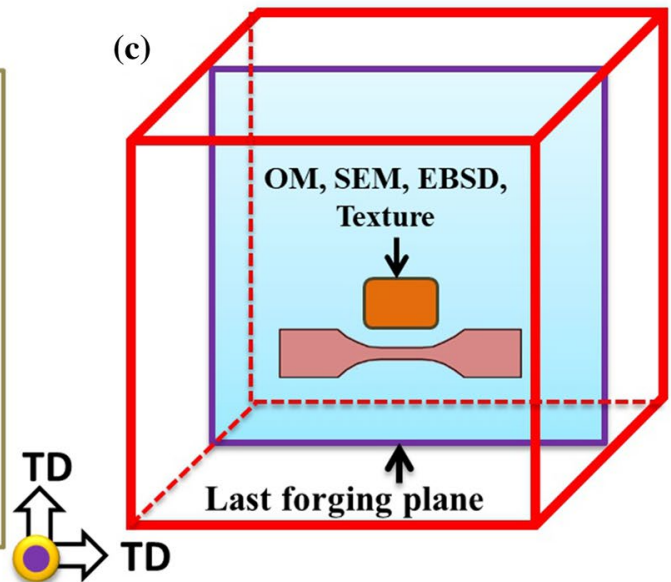

Fig. 1 a Schematic diagram of the MDIF process, $\mathbf{b}$ extension in the forging passes up to 50 at $450{ }^{\circ} \mathrm{C}$, $\mathbf{c}$ machined out samples position from the center of MDIFed sample

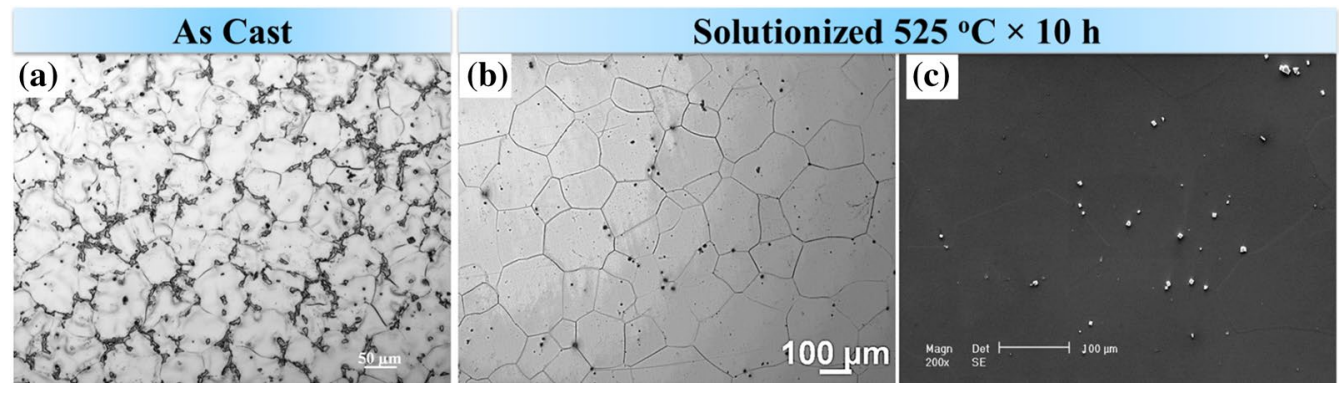

Fig. 2 a Cast microstructure of GW94 Mg alloy as shown in OM image, b solid solution-treated microstructure, c SEM image of solid solutiontreated sample

(Fig. 3c) which are likely to reside near the original grain boundaries and also tend to cover the interiors of the grain. After MDIF at $500{ }^{\circ} \mathrm{C}$, almost DRXed microstructure can be found (Fig. 3d), yet the DRX grains are slightly larger than that obtained in sample MDIFed at $450{ }^{\circ} \mathrm{C}$. Overall, the optical microstructures (Fig. 3) exposed that MDIF at a higher temperature such as $450{ }^{\circ} \mathrm{C}$ and $500{ }^{\circ} \mathrm{C}$ seems more appropriate to achieve a homogeneous microstructure in present GW94 alloy.
In order to analyze the recrystallized or deformed grains, twinning types, and their frequencies, the MDIFed specimens were examined by EBSD measurement. High-angle grain boundaries (HAGBs), low-angle grain boundaries (LAGBs), $\{10-12\}$ extension, $\{10-11\}$ contraction, and $\{10-11\}-\{10-12\}$ double twinning boundaries are tinted in different colors. The relaxation in angular difference to measure the twin boundaries was considered $5^{\circ}$ to the ideal value. 


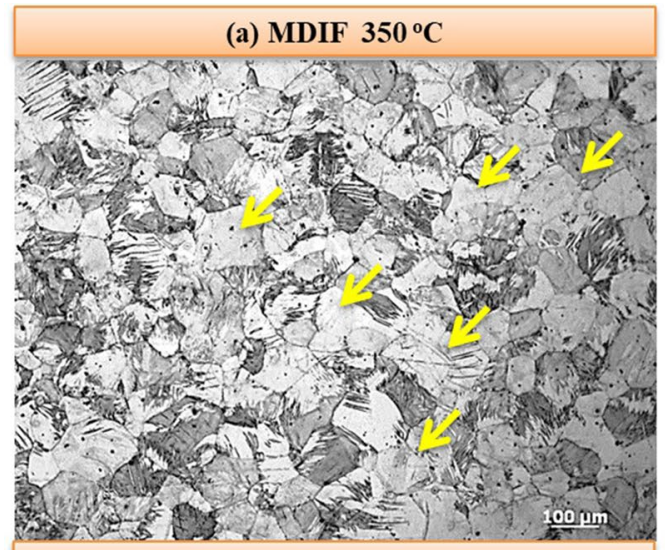

(c) MDIF $450^{\circ} \mathrm{C}$

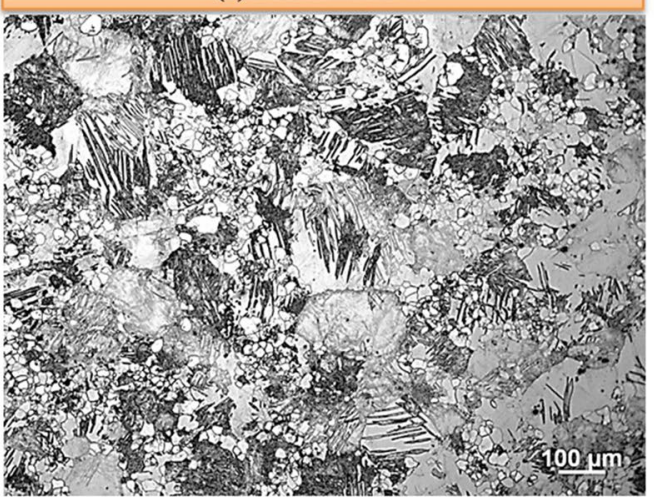

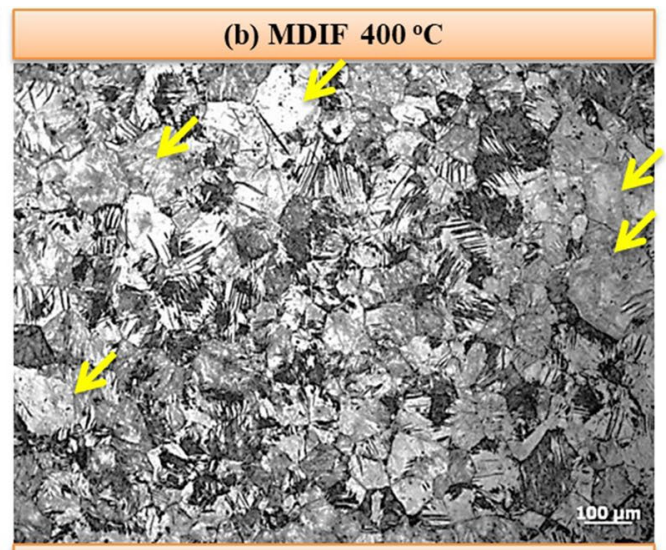

(d) MDIF $500^{\circ} \mathrm{C}$

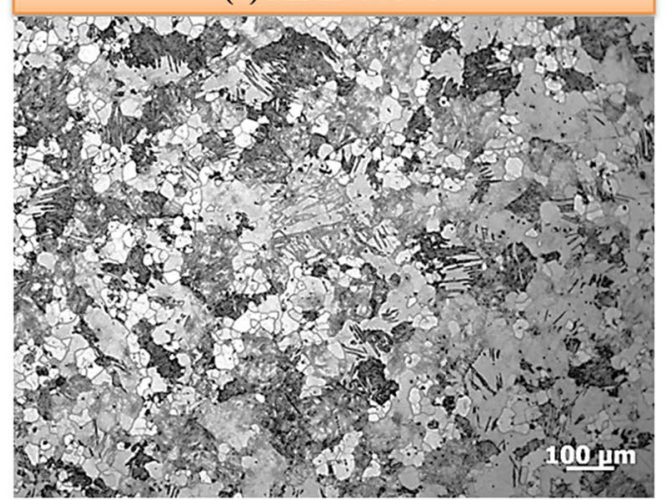

Fig. 3 The optical microstructures of GW94 Mg alloy MDIF 30 passes at different temperatures: a $350{ }^{\circ} \mathrm{C}, \mathbf{b} 400{ }^{\circ} \mathrm{C}, \mathbf{c} 450{ }^{\circ} \mathrm{C}, \mathbf{d ~} 500{ }^{\circ} \mathrm{C}$

Figure $4 \mathrm{a}, \mathrm{b}$ displays the EBSD IPF map of forged GW94 alloy for 30 passes at $400{ }^{\circ} \mathrm{C}$. Twinning was the main deformation mode as plentiful $\{10-12\}$ extension twins were detected in the entire microstructure. Lower (CRSS) critical resolved shear stress, i.e., $(\sim 2-3 \mathrm{MPa})$ for $\{10-12\}$ extension twins may contribute to their existence [23, 24]. In order to explore the microstructure in detail, magnified images are selected in Fig. 4a, b which reveals the parallel twins in some particular regions (Fig. 4c) that are deviated by almost $\sim 86^{\circ}$ from the matrix. Indeed, the following results are dissimilar with the results obtained in Ref. [25] that $\{10-12\}$ extension twins including DRXed grains were obtained, however, in this case, the $\{10-12\}$ extension twins contributed in another way, i.e., they divided effectually the initial coarse grains. Afterward, plenty of LAGBs formed in those twins, accordingly splitting them into numerous parts (Fig. 4d). Besides, the LAGBs in twins few LAGBs parallels with the twin boundaries (TBs) were also noticed (Fig. 4e), thus reflecting not only the partition and finally refinement of the original coarse grains but also specifies an interaction between the $\{10-12\}$ extension twin boundaries and dislocation slips [26]. Moreover, the grain occupied by LAGBs, i.e., subgrain converted to the new DRX grains with increasing strain has been proposed before in Mg alloys [26].
Indeed, very few regions with fine DRX grains $(3-5 \mu \mathrm{m})$ were observed; however, they seem to be twin intersected regions as some residual twin boundaries can be identified beside the DRX grains (Fig. 4f), which has been suggested before to provide effective nucleation sites for recrystallization $[27,28]$. Generally, after MDIF 30 passes at $400{ }^{\circ} \mathrm{C}$, a dense twinned microstructure without significant recrystallization was obtained. The $\{10-12\}$ extension twins vividly divided the coarse initial grains and new DRX grains tends to nucleate at the twinning regions; however, the alloy fails to obtain a fully recrystallized structure and display an incompletion of the recrystallization process.

The EBSD observations of GW94 alloy at $450{ }^{\circ} \mathrm{C}$ after 30 and 50 forging passes were also studied in detail. The comprehensive descriptions about the sample MDIFed for 30 and 50 passes can be found in our previous work [8] while for the purpose of assessment, we will discuss it briefly here. In comparison to the sample MDIFed at $400{ }^{\circ} \mathrm{C}$ (Fig. 4), the frequency of the twin boundaries at $450{ }^{\circ} \mathrm{C}$ was $12.5 \%$, which is almost double to $7.5 \%$ at $400{ }^{\circ} \mathrm{C}$, but almost all the twinning boundaries were recognized $\{10-12\}$ extension twins. With the increase in forging passes up to 50 , the rate of recurrence of those $\{10-12\}$ extension twins decreases from 12.5 to $3.5 \%$, while a lot of fine DRX grains were also 

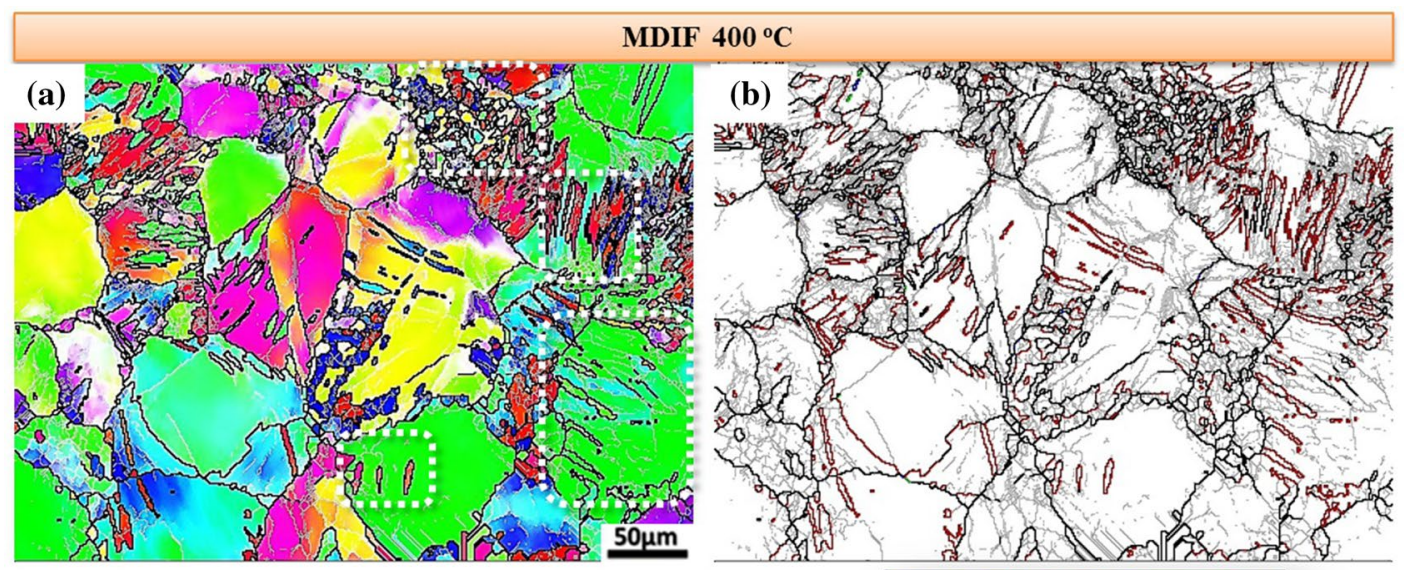

(c) Parallel Twins

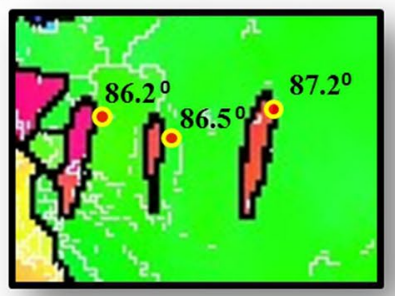

(d) LAGBs in Twin

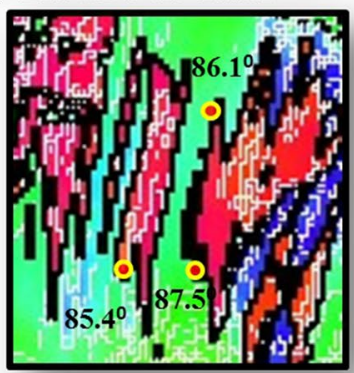

(e) LAGBs near TBs
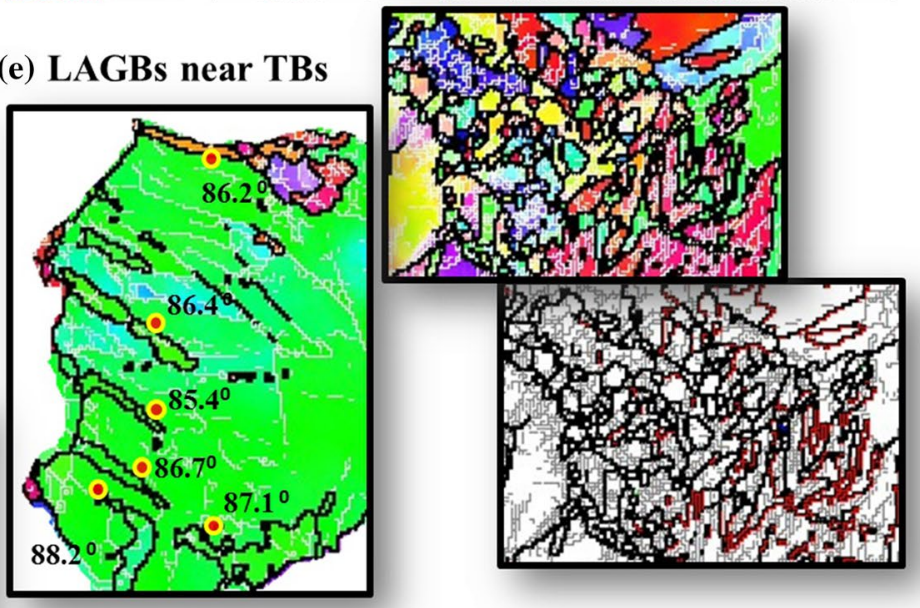

(f) Twins residue \& twin induce DRX grains
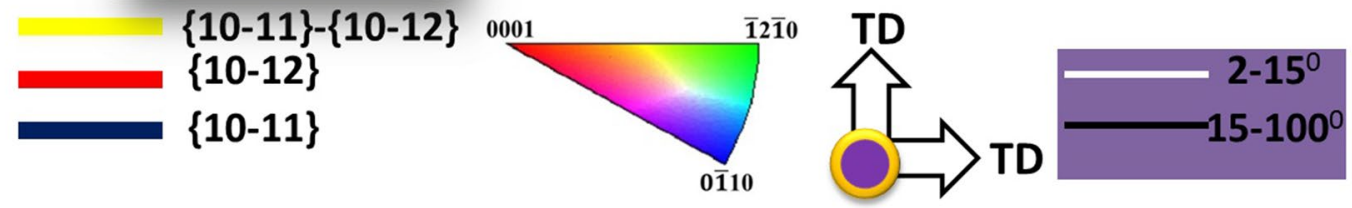

Fig. 4 a Inverse pole figure map, b corresponding grain boundary map of the GW94 alloy after MDIF 30 passes at $400{ }^{\circ} \mathrm{C}$, whereas $\mathbf{c}-\mathbf{f}$ the enlarged IPF maps selected in $\mathbf{a}, \mathbf{b}$ displaying the formation of extension twins and low-angle grain boundaries

observed [8]. Indeed, the beneficial $\{10-12\}$ extension twin promoted the DRX behavior during the MDIF process at $450{ }^{\circ} \mathrm{C}$ for 30 passes and following 50 forging passes with almost very few twins, the fine DRX grains percent rises up to $25 \%$ and occupied most of the microstructure [8]. However, recrystallization process in the present GW94 alloy, even at $450{ }^{\circ} \mathrm{C}$, seems much sluggish than that initiated by the double and contraction twins in AZ61 alloy [16] as a complete recrystallized microstructure was obtained after MDIF 30 passes, following the same forging technique [16].

Figure 5a, b represents the IPF maps of GW94 alloy forged for 30 passes at $500{ }^{\circ} \mathrm{C}$. An inhomogeneous relatively coarse grain microstructure containing very few twinned grains was obtained after MDIFed for 30 passes at $500{ }^{\circ} \mathrm{C}$. Evidently, the same high strain rate forging process was followed at $500{ }^{\circ} \mathrm{C}$ but the absence of significant twin induces DRX because high temperature may result in a relatively coarse-grained inhomogeneous microstructure. Certainly, the $500{ }^{\circ} \mathrm{C}$ temperature suppressed the occurrence of twinning during the MDIF; however, few twins were still witnessed (Fig. 5c) which could be attributed to the high strain rate MDIF. In fact, MDIF offers very limited time, during which the activated slips may not alter the crystal orientation suddenly, and however, twinning deviates it abruptly and tends to accommodate the induced strain [29]. Indeed, many LAGBs were detected in 

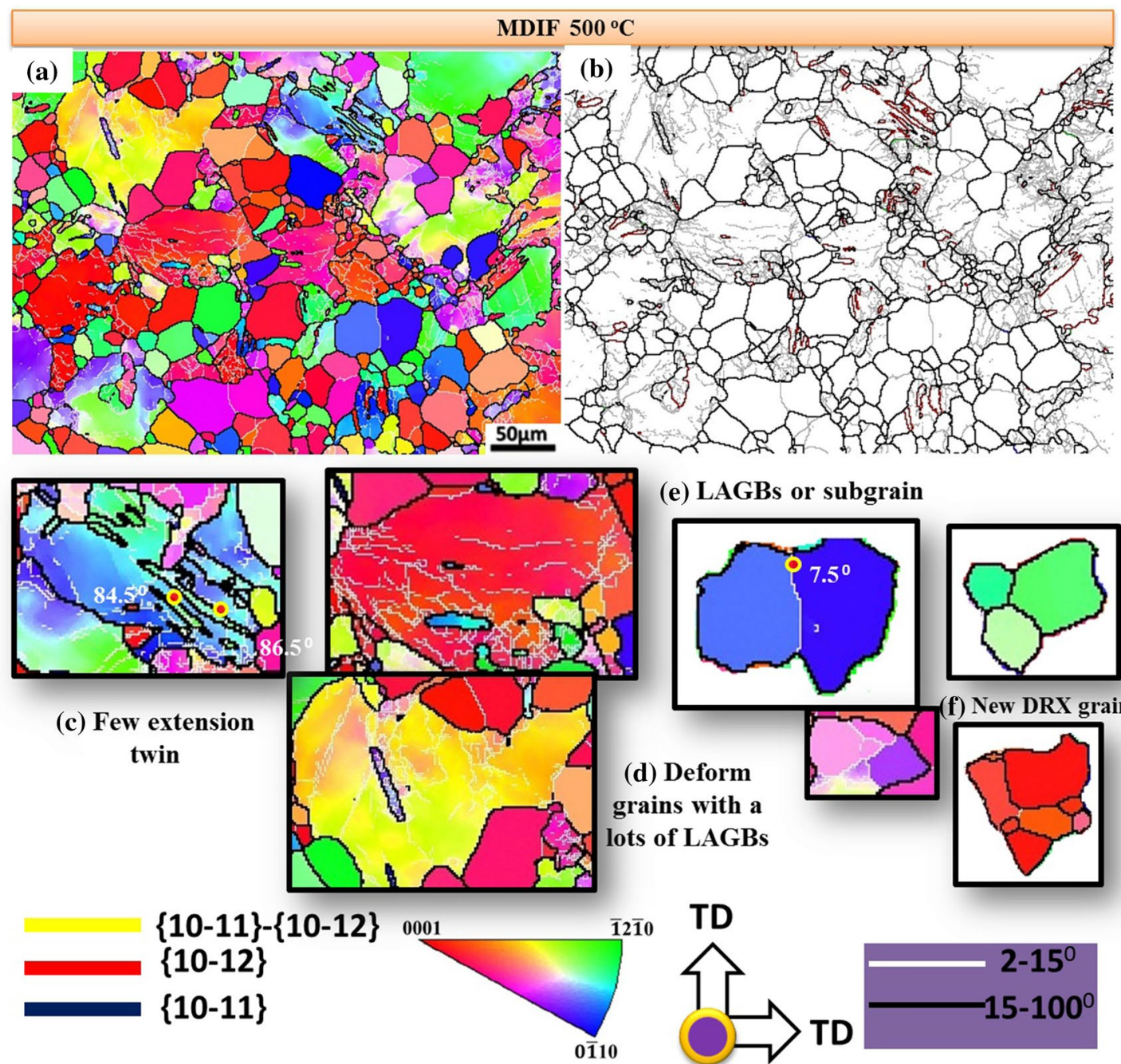

(e) LAGBs or subgrain
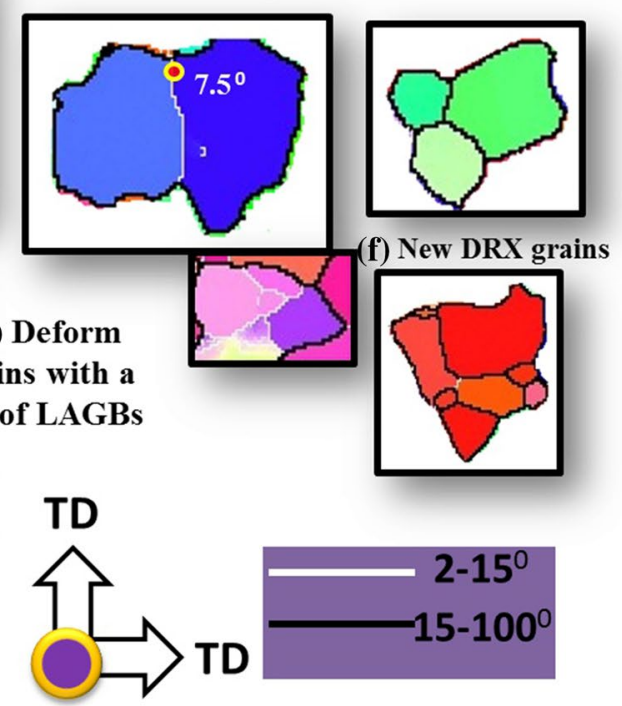

Fig. 5 a Inverse pole figure map, b corresponding grain boundary map of the GW94 alloy after MDIF 30 passes, where c-e the enlarged IPF maps selected in a, showing few twins and lots of LAGBs in coarse grain with LAGBs and new DRX grains

some deform grains (Fig. 5d), which reveals the increased level of dynamic recovery (DRV) because of a higher dislocation slipping behavior at $500{ }^{\circ} \mathrm{C}$ and hence assist the grain refinement process. Moreover, new grains with HAGBs containing subgrain were also observed (Fig. 5e), which will be transformed progressively into a dynamically recrystallized grain with proceeded deformation (Fig. 5f). Generally, in the deformed structure, LAGBs come from the accumulated dislocations [4]. With the increase in strain, those LAGBs may absorb additional dislocations and transform into HAGBs, i.e., typically a CDRX process [4]. Nevertheless, it should be noted that the average size of those recrystallized grains at $500{ }^{\circ} \mathrm{C}$ is approximately $\sim 15 \mu \mathrm{m}$, i.e., almost five times greater than that the size of DRX grain $(2-3 \mu \mathrm{m})$ obtained after 50 passes at $450{ }^{\circ} \mathrm{C}$. Higher grain boundary mobility and diffusion behavior at $500^{\circ} \mathrm{C}$ should lead in higher driving energies, thus resulting in a coarser grain structure than the prior ones [30].

\subsection{Texture}

Figure 6a-c demonstrates the pole figures of GW94 alloy forged at different temperatures. Generally, a strong basal texture formed during the deformation, e.g., rolling or extrusion, because of the widespread instigation of extension twins and basal slips in wrought Mg alloys [28]. Nevertheless, in the present investigations, a non-basal weak texture was obtained after each MDIF process at a different temperature which could be attributed to the small pass strain and changes in the forging plane at each pass during the MDIF process.

Moreover, twinning may also affect the process of texture development. If the compression stress is perpendicular 


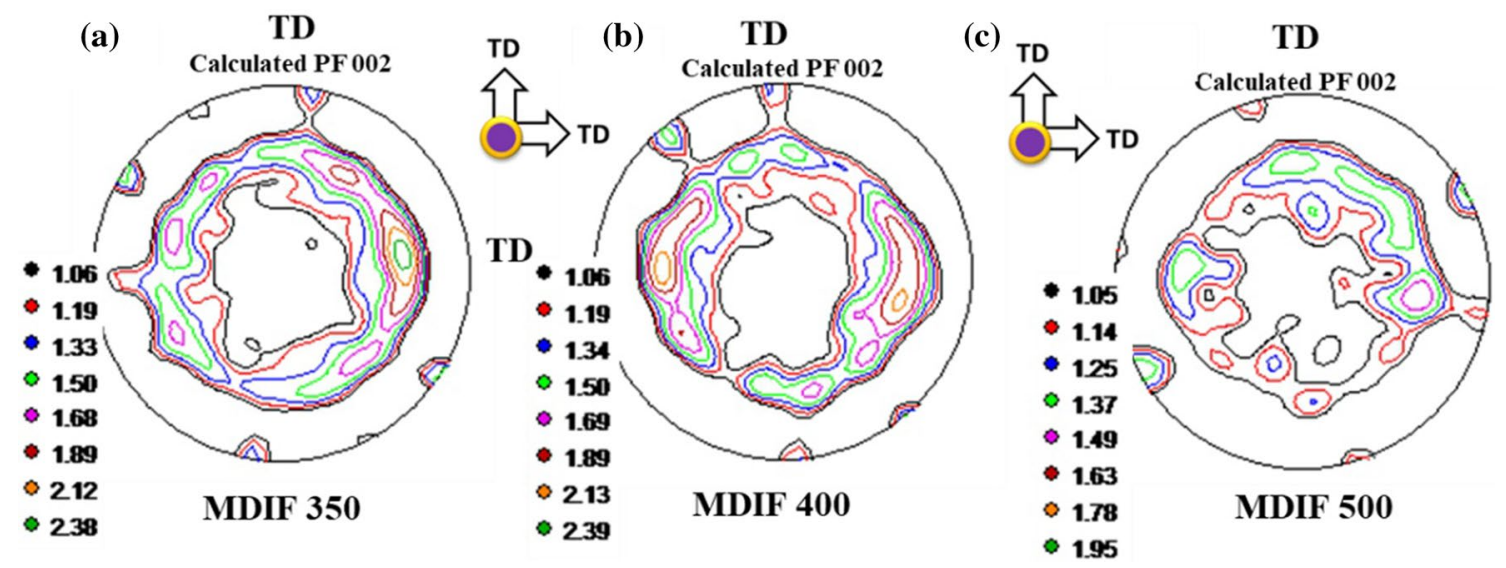

Fig. $6\{0002\}$ Pole figures of MDIFed GW94 alloy MDIF for 30 passes: a $350{ }^{\circ} \mathrm{C}, \mathbf{b} 400{ }^{\circ} \mathrm{C}, \mathbf{c} 500{ }^{\circ} \mathrm{C}$

to the $c$-axis of the (hexagonal close pack) hcp unit cell, $\{10-12\}$ extension twin occurs within a parent grain, ensuring a change in crystal orientation about $\sim 86^{\circ}$. The basal plane of that particular twinned grains after $\{10-12\}$ twinning should rotate by $\sim 86^{\circ}$, which means precisely the basal plane almost perpendicular and $c$-axis parallel to the last forging direction (LFD). Hence, on the bases of arbitraryoriented initial grains (solutionized conditions), randomly directed twins were produced that consequently developed a non-basal texture during the process of MDIF. Additionally, strain employment during the deformation also has a significant effect on texture formation. Wu et al. [31] found a basal texture in $\mathrm{Mg}-\mathrm{Gd}-\mathrm{Zn}$ alloy even after MDF process and credited it to the large strain employed 0.5 in the final pass of the forging process. However, Yang et al. [32] observed the rapidly amplified grain rotation at the strain greater than 0.1 after hot compression of the AZ31 alloy, thus signifying that deformation by large strain in unidirectional compression source strong basal texture. Therefore, the present results suggest such a minor strain per pass $\sim 0.05$ combined with the multi-direction forging results in a non-basal texture after 30 passes at each temperature.

\section{Discussion}

The present experiments reveal evidence for average grain size and twin percentage during the MDIF carried out at different temperatures as shown in Fig. 7. At $400{ }^{\circ} \mathrm{C}$, only $\{10-12\}$ extension twins were initiated by the MDIF process. The activated twins proficiently segmented and subdivided the parent grains and performed an essential role to offer an additional mode to accommodate the strain [29]; however, they did not succeed in creating an obvious DRX, indicating insufficient driven thermal energy at $400{ }^{\circ} \mathrm{C}$. Meanwhile, twin-assisted continuous DRX mainly

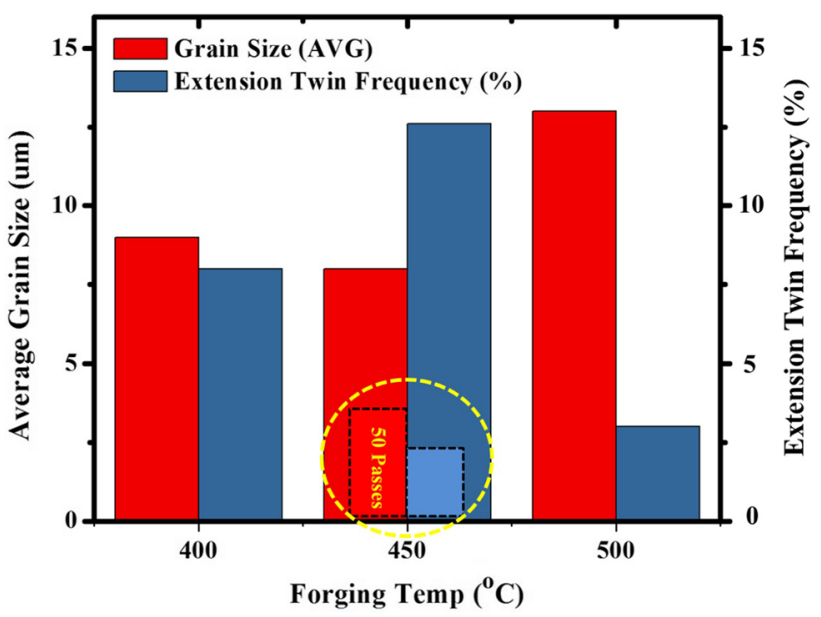

Fig. 7 Relationship among average grain size, twins percentage and forging temperature of MDIFed GW94 alloy obtained from EBSD data. The region inscribes by yellow circle that reveals the twin's percentage and average grain size at MDIF 50 passes

contributed to the grain refinement at $450{ }^{\circ} \mathrm{C}$ [8]. Generally, in $\mathrm{Mg}$ alloys, $\{10-12\}$ extension twins are believed to accommodate the internal stresses and grow easily during the deformation process [33]. In comparison to $\{10-11\}$ contraction and $\{10-11\}-\{10-12\}$ double twins, $\{10-12\}$ extension twins are not considered as influential to DRX nucleation [34-36]. However, with a further increment of forging passes up to 50, the MDIF process was progressively dominated by a $\{10-12\}$ extension twin-assisted dynamic recovery process that consequently consumed most of the deformed microstructure and almost a fine grain recrystallized microstructure was obtained (Fig. 7). Certainly, the $500{ }^{\circ} \mathrm{C}$ temperature suppressed the occurrence of twinning during the MDIF process. The twinning suppression results in a relatively large average grain size, while twins as influential sites for DRX were also reduced. Indeed, new DRX 
grain appeared; however, their sizes were much bigger than the ones created after 50 forging passes at $450{ }^{\circ} \mathrm{C}$. With regard to their relatively large average size at $500{ }^{\circ} \mathrm{C}$, Xia et al. [30] proposed that it is governed by Zener-Hollomon parameter, i.e.,

$Z=\dot{\varepsilon} \exp (Q / R T)$,

where $\dot{\varepsilon}$ is strain rate, $Q$ is activation energy, and $R$ and $T$ are ideal gas and temperature constants, respectively. The Eq. (4.1) suggests that the average size of recrystallized grains will increase with the rise in temperature. Additionally, solute concentrations of RE elements at the GBs or TBs in $\mathrm{Mg}$ alloys may also affect their recrystallization process [37]. They tend to retard their mobilities during the recrystallization, which are overcome by sufficient thermal energy during the deformation process $[38,39]$. Therefore, consistent with Ref. [40], the diffusion rate of RE in $\mathrm{Mg}$ above $400{ }^{\circ} \mathrm{C}$ is around $\sim 3 \times 10^{-15} \mathrm{~m}^{2} / \mathrm{s}$, which is almost thirty times greater than the diffusion rate calculated at $350{ }^{\circ} \mathrm{C}$ and must be larger at $500{ }^{\circ} \mathrm{C}$. Therefore, the mentioned Zener-Hollomon parameter and the increased solute diffusion behavior at $500{ }^{\circ} \mathrm{C}$ may result in relatively large DRX grains after MDIF.

Furthermore, usually slips and twinning compete during the deformation at elevated temperature, and also, the CRSS values for non-basal slips decrease intensively with the increasing temperature. As reported before in Refs. $[33,41]$, the pyramidal slip system is easy to be activated above $300{ }^{\circ} \mathrm{C}$, while it occurs more significantly above the $400{ }^{\circ} \mathrm{C}$. In contrast, the grain size, strain rate, also temperature largely affect the twin formation. Indeed, the strain rate during MDIF at each temperature was almost the same but deformation at low temperatures mostly favors twinning while the decreasing grain sizes diminish their formation due to the Hall-Petch effect. i.e., specifically, the twins are difficult to be activated at reduced grain size [42-45]. Therefore, at the lower temperatures such as $350{ }^{\circ} \mathrm{C}$ and $400{ }^{\circ} \mathrm{C}$, twinning was the dominated deformation behavior, however, at the intermediate temperature, i.e., $450{ }^{\circ} \mathrm{C}$ beside the twinning activation, twin-induced DRX also occurred which significantly contributed to the grain refinement up to 50 forging passes as specified by the yellow circle in Fig. 7. While, during MDIF at $500^{\circ} \mathrm{C}$, non-basal slips were gradually activated due to its decreasing CRSS. It has been well known that due to an increase in the dislocation slips a greater amount of internal energies accumulate, which might perform a key role in DRX nucleation [46]. DRX promoted by different dislocation slips was also studied deeply before [47] and witnessed by Koike et al. [33, 48] in the AZ31 alloy. In addition, the dislocation lines related to the basal slips were also found interrelated to the LAGBs in Ref. [49]. The same LAGBs were also observed after the MDIF 30 passes at $500{ }^{\circ} \mathrm{C}$ which surely contributed to the grain refinement process. Thus, after the MDIF 30 passes at $500{ }^{\circ} \mathrm{C}$, due to the higher temperature, the slipping overawed the dominant twining behavior. However, due to the higher temperature, the equiaxed DRX grains experienced substantial growth, which deteriorates to obtain a fine grain microstructure.

\section{Conclusions}

1. The $\{10-12\}$ extension twins were the dominant deformation mode after the MDIF carried out at temperatures lower than $450{ }^{\circ} \mathrm{C}$, and the onset of dynamic recrystallization was negligible.

2. At the temperature of $450{ }^{\circ} \mathrm{C}$, the $\{10-12\}$ extension twins divided the initial coarse grain and promoted continuous DRX behavior. With the extension in forging passes up to 50, the twin matrix laminates gradually converted into fine DRX grains.

3. After MDIF at $500{ }^{\circ} \mathrm{C}$, the twinning formation was suppressed due to a higher temperature. New DRX grains were observed, but their sizes were much bigger than the ones formed after 50 passes at $450{ }^{\circ} \mathrm{C}$ which is credited to the larger diffusion rates and grain boundary mobilities at $500{ }^{\circ} \mathrm{C}$.

4. A non-basal weak texture with low intensity was obtained after MDIF at each temperature, which is attributed to the multi-directional forging method and the small strain employed in each pass.

Acknowledgements This work was supported by the National Key Research and Development Program of China (No. 2016YFB0301104), the National Natural Science Foundation of China (NSFC, Nos. 51301173, 51531002 and 51601193), and the National Basic Research Program of China (973 Program, No. 2013CB632202).

\section{References}

[1] S. Zhu, H. Yan, X. Liao, S. Moody, G. Sha, Y. Wu, S. Ringer, Acta Mater. 82, 344 (2015)

[2] H.E. Friedrich, B.L. Mordike, Magnesium Technology: Metallurgy, Design Data, Applications (Springer, Berlin, 2006), p. 207

[3] S. Shah, M. Jiang, D. Wu, U. Wasi, R. Chen, Acta Metall. Sin. (Engl. Lett.) 31, 923 (2018)

[4] M. Jiang, C. Xu, H. Yan, G. Fan, T. Nakata, C. Lao, R. Chen, S. Kamado, E. Han, B. Lu, Acta Mater. 157, 53 (2018)

[5] M. Hong, S. Shah, D. Wu, R. Chen, X. Du, N. Hu, Y. Zhang, Met. Mater. Int. 22, 1091 (2016)

[6] L. Li, Mater. Sci. Eng. A 528, 7178 (2011)

[7] T. Peng, Q. Wang, J. Lin, M. Liu, H.J. Roven, Mater. Sci. Eng. A 528, $1143(2011)$

[8] S. Shah, D. Wu, W. Wang, R. Chen, Mater. Sci. Eng. A 702, 153 (2017)

[9] T. Homma, N. Kunito, S. Kamado, Scr. Mater. 61, 644 (2009) 
[10] C. Xu, S. Xu, M. Zheng, K. Wu, E. Wang, S. Kamado, G. Wang, X. Lv, J. Alloys Compd. 524, 46 (2012)

[11] C. Xu, M. Zheng, S. Xu, K. Wu, E. Wang, S. Kamado, G. Wang, X. Lv, Mater. Sci. Eng. A 547, 93 (2012)

[12] H. Zhang, S. Chen, M. Cheng, C. Zheng, S. Zhang, Acta Metall. Sin. (Engl. Lett.) 32, 1122 (2019)

[13] Z.J. Yu, C. Xu, J. Meng, K. Liu, J.L. Fu, S. Kamado, Mater. Sci. Eng. A 762, 138080 (2019)

[14] K. Wang, J. Wang, X. Peng, S. Gao, H. Hu, L. Zeng, F. Pan, Mater. Sci. Eng. A 748, 100 (2019)

[15] H. Miura, T. Maruoka, X. Yang, J. Jonas, Scr. Mater. 66, 49 (2012)

[16] M. Jiang, H. Yan, R. Chen, J. Alloys Compd. 650, 399 (2015)

[17] M. Jiang, H. Yan, R. Chen, Mater. Sci. Eng. A 621, 204 (2015)

[18] Y. Wu, H. Yan, J. Chen, Y. Du, S. Zhu, B. Su, Mater. Sci. Eng. A 556, 164 (2012)

[19] L. Tang, C. Liu, Z. Chen, D. Ji, H. Xiao, Mater. Des. 50, 587 (2013)

[20] S.Q. Zhu, H.G. Yan, J.H. Chen, Y.Z. Wu, J.Z. Liu, J. Tian, Scr. Mater. 63, 985 (2010)

[21] L. Gao, R. Chen, E. Han, Mater. Sci. 44, 4443 (2009)

[22] J.L. Li, N. Zhang, X.X. Wang, D. Wu, R.S. Chen, Acta Metall. Sin. (Engl. Lett.) 31, 189 (2018)

[23] A. Kaya, Fundam. Magnes. Alloy Metall. 33, 35 (2013)

[24] M. Barnett, Z. Keshavarz, X. Ma, Metall. Mater. Trans. A 37, 2283 (2006)

[25] M.D. Nave, M.R. Barnett, Scr. Mater. 51, 881 (2004)

[26] T. Al-Samman, K.D. Molodov, D.A. Molodov, G. Gottstein, S. Suwas, Acta Mater. 60, 537 (2012)

[27] L. Lu, J. Zhao, L. Liu, G. Wang, Mater. Sci. Technol. 32, 104 (2016)

[28] I. Basu, T. Al-Samman, Acta Mater. 96, 111 (2015)

[29] J.W. Christian, S. Mahajan, Prog. Mater Sci. 39, 96 (1995)

[30] X. Xia, Q. Chen, Z. Zhao, M. Ma, X. Li, K. Zhang, J. Alloys Compd. 623, 62 (2015)
[31] D. Wu, R. Chen, W. Tang, E. Han, Mater. Des. 41, 306 (2012)

[32] X.Y. Yang, Z.S. Ji, H. Miura, T. Sakai, Trans. Nonferrous Met. Soc. China 19, 55 (2009)

[33] J. Koike, T. Kobayashi, T. Mukai, H. Watanabe, M. Suzuki, K. Maruyama, K. Higashi, Acta Mater. 51, 2055 (2003)

[34] X. Li, P. Yang, L.N. Wang, L. Meng, F. Cui, Mater. Sci. Eng. A 517, 160 (2009)

[35] Y. Xin, H. Zhou, H. Yu, R. Hong, H. Zhang, Q. Liu, Mater. Sci. Eng. A 622, 178 (2015)

[36] P. Changizian, A. Zarei-Hanzaki, H. Abedi, Mater. Sci. Eng. A 558, 44 (2012)

[37] L. Priester, Epilogue (Springer, Dordrecht, 2013), p. 217

[38] J. Zhang, Y. Dou, Y. Zheng, Scr. Mater. 80, 17 (2014)

[39] M. Bugnet, A. Kula, M. Niewczas, G. Botton, Acta Mater. 79, 66 (2014)

[40] I. Basu, K. Pradeep, C. Mießen, L. Barrales-Mora, T. Al-Samman, Acta Mater. 116, 77 (2016)

[41] J. Koike, Metall. Mater. Trans. A 36, 1689 (2005)

[42] M. Barnett, Z. Keshavarz, A. Beer, D. Atwell, Acta Mater. 52, 5093 (2004)

[43] J. Sun, P. Trimby, F. Yan, X. Liao, N. Tao, J. Wang, Acta Mater. 79, 47 (2014)

[44] Q. Yu, L. Qi, K. Chen, R.K. Mishra, J. Li, A.M. Minor, Nano Lett. 12, 887 (2012)

[45] A. Ghaderi, M.R. Barnett, Acta Mater. 59, 7824 (2011)

[46] M.O. Pekguleryuz, K. Kainer, A.A. Kaya, Fundam. Magnes. Alloy. Metall. 33, 35 (2013)

[47] J. Del Valle, M.T. Pérez-Prado, O. Ruano, Mater. Sci. Eng. A 355, 68 (2003)

[48] J. Koike, R. Ohyama, T. Kobayashi, M. Suzuki, K. Maruyama, Mater. Trans. 44, 445 (2003)

[49] B. Shi, R. Chen, W. Ke, Mater. Sci. Eng. A 560, 62 (2013) 